\title{
Predicting the Distribution and Properties of Buried Submarine Topography on Continental Shelves
}

\author{
Patricia Wiberg \\ Department of Environmental Sciences, University of Virginia \\ P.O. Box 400123, Charlottesville, VA 22904-4123 \\ phone: (434) 924-7546 fax: (434) 982-2137 email: pw3c@virginia.edu \\ Alan Howard \\ Department of Environmental Sciences, University of Virginia \\ P.O. Box 400123, Charlottesville, VA 22904-4123 \\ phone: (434) 924-0563 fax: (434) 982-2137 email: ah6p@virginia.edu
}

Grant Number: N00014-00-1-0822

\section{LONG-TERM GOALS}

The long-term goal of the Geoclutter modeling project is to predict the distribution and properties of buried channels that may be responsible for geoclutter on continental margins of interest.

\section{OBJECTIVES}

The overall objectives of our project are 1) to determine the characteristics of channel features that can form when the present continental shelf is subaerially exposed during low sea-level conditions and 2) to determine whether these features would be buried when sea-level returned to its present position and, if so, how deeply. During FY02, our objectives have been to improve the scaling of the landscape evolution model, to investigate the controls on incision rates, to add a coastal component to the model, and to add continental shelf processes to the landscape evolution model.

\section{APPROACH}

Our approach is to develop numerical simulation models of landscape evolution and shelf sediment transport to investigate the development of topography on the shelf during sea-level low stands and the burial of that topography during high sea-level conditions. Our model is based on Alan Howard's drainage basin evolution model. Alan Howard and Sergio Fagherazzi (post-doc) have adapted, tested, and applied the landscape evolution model to coastal plain settings and exposed continental shelves. Patricia Wiberg and Sergio Fagherazzi are developing and implementing coastal and shelf transport modules for the landscape evolution model.

\section{WORK COMPLETED}

During FY02, we completed 1) a sensitivity analysis of the drainage basin evolution model to different initial conditions and model parameter values characteristic of continental shelves and coastal plains; 2) a 2-D nearshore morphdynamic model was developed to better represent processes controlling shoreline position and transfer of sediment between the terrestrial and marine domains of the model during changing sea level; 3) coupling of the nearshore model with the landscape evolution model; 4) 


\section{Report Documentation Page}

Form Approved

OMB No. 0704-0188

Public reporting burden for the collection of information is estimated to average 1 hour per response, including the time for reviewing instructions, searching existing data sources, gathering and maintaining the data needed, and completing and reviewing the collection of information. Send comments regarding this burden estimate or any other aspect of this collection of information,

including suggestions for reducing this burden, to Washington Headquarters Services, Directorate for Information Operations and Reports, 1215 Jefferson Davis Highway, Suite 1204, Arlington

VA 22202-4302. Respondents should be aware that notwithstanding any other provision of law, no person shall be subject to a penalty for failing to comply with a collection of information if it

does not display a currently valid OMB control number.

1. REPORT DATE

30 SEP 2002

2. REPORT TYPE

3. DATES COVERED

00-00-2002 to 00-00-2002

4. TITLE AND SUBTITLE

Predicting the Distribution and Properties of Buried Submarine

Topography on Continental Shelves

6. AUTHOR(S)

5. CONTRACT NUMBER

5b. GRANT NUMBER

5c. PROGRAM ELEMENT NUMBER

5d. PROJECT NUMBER

5e. TASK NUMBER

5f. WORK UNIT NUMBER

7. PERFORMING ORGANIZATION NAME(S) AND ADDRESS(ES)

8. PERFORMING ORGANIZATION

REPORT NUMBER

Department of Environmental Sciences, University of Virginia,,P.O. Box

400123,,Charlottesville,,VA, 22904

9. SPONSORING/MONITORING AGENCY NAME(S) AND ADDRESS(ES)

10. SPONSOR/MONITOR'S ACRONYM(S)

11. SPONSOR/MONITOR'S REPORT $\operatorname{NUMBER}(\mathrm{S})$

12. DISTRIBUTION/AVAILABILITY STATEMENT

Approved for public release; distribution unlimited

13. SUPPLEMENTARY NOTES

14. ABSTRACT

The long-term goal of the Geoclutter modeling project is to predict the distribution and properties of buried channels that may be responsible for geoclutter on continental margins of interest.

15. SUBJECT TERMS

16. SECURITY CLASSIFICATION OF:

a. REPORT

unclassified b. ABSTRACT

unclassified c. THIS PAGE

unclassified
17. LIMITATION OF ABSTRACT

Same as Report (SAR)
18. NUMBER OF PAGES

6 19a. NAME OF

RESPONSIBLE PERSON 
revising the landform simulation code to make if fully dimensional and performing a literature search to define the ranges of natural variation of rates of geomorphic processes and sediment material properties that are represented in the model. A draft report on the parameterization of fluvial and hillslope processes has been prepared and is available upon request.

\section{RESULTS}

1 ) A sensitivity analysis of the fluvial model to different initial conditions and model parameter values was performed. Different shelf geometries, sediment supply conditions, and sea level curves were utilized during these tests. Results show the strong influence of the river equilibrium configuration (i.e. if the river is at grade (Figure 1) or out of grade (Figure 2) with respect to the shelf slope) and sea levels that fall below the shelf break on the degree of incision of the shelf. The deepest incision was associated with headward cutting nickpoints that initiated at the shelf-slope break. Intermediate incision depths were associated with the extension of terrestrial rivers across the shelf when sea level fell. Minor incision depths were produced by internally developed channels related to variations in shelf topography. The geometry and thickness of sediments deposited in deltas and estuaries had a minor influence on the total channel incision, but were of fundamental importance for the spatial development of the channel network (Figure 1). These results are described in a paper soon to be submitted (Howard A.D., Fagherazzi S., and Wiberg P.L., Modeling fluvial erosion of continental shelves during sea level low stands).

2) In order to understand what part of the terrestrial topography is preserved during transgression, with emphasis on the system of fluvial channels, and what part is instead reworked by coastal processes, a nearshore sediment transport model has been developed. The model was first implemented in two dimensions in order to test the results and understand the role of the different processes at play. The two-dimensional model conserves the equilibrium beach profile and updates its position during sea level transgression and regression. The conservation of the beach cross sectional profile, together with sea level changes, gives rise to a system of barrier islands (Figure 3). The formation and evolution of these barrier islands are particularly important for the bathymetry of wave-dominated shelves. Barrier islands form by the combined action of waves, sea level oscillations, and sediment supply, whereas washover deposits caused by intense storms allow the barrier island to migrate landward during transgression. The schematic representation of the model links the existence and evolution of barrier islands to the interconnected relationships among the accommodation space in the back barrier area (the volume to be filled in order to translate the barrier island), the rate of sea level change, and the average volume of sediment deposited in the back barrier system by overwash.

3) The fluvial incision and deposition model has been coupled with a $3 \mathrm{D}$ version of the nearshore sediment transport model, adapted for use on continental shelves. A further important agent for sediment redistribution in the nearshore area, namely the longshore current, was added using a simplified implementation to characterize longshore transport rates as a function of coastline orientation and wave direction. The 3D model produces realistic results in the nearshore area, with the formation and migration of barrier islands as a function of the rate of sea level rise, shelf slope, and sediment supply. The coupling with the fluvial incision and deposition model will provide an estimate of the role of waves on the preservation or elimination of terrestrial topography during transgression. A diffusive model of shelf sediment transport developed last year has been added to the 2D shoreface model and will be implemented in the full landscape evolution model during the coming year. Initial tests indicate that the shoreface model tends to result in rates topography adjustment of the shelf profile 
that are too large. The problem, which appears to be associated with higher-than-expected seabed resistance to erosion, will be explored further during the coming year.
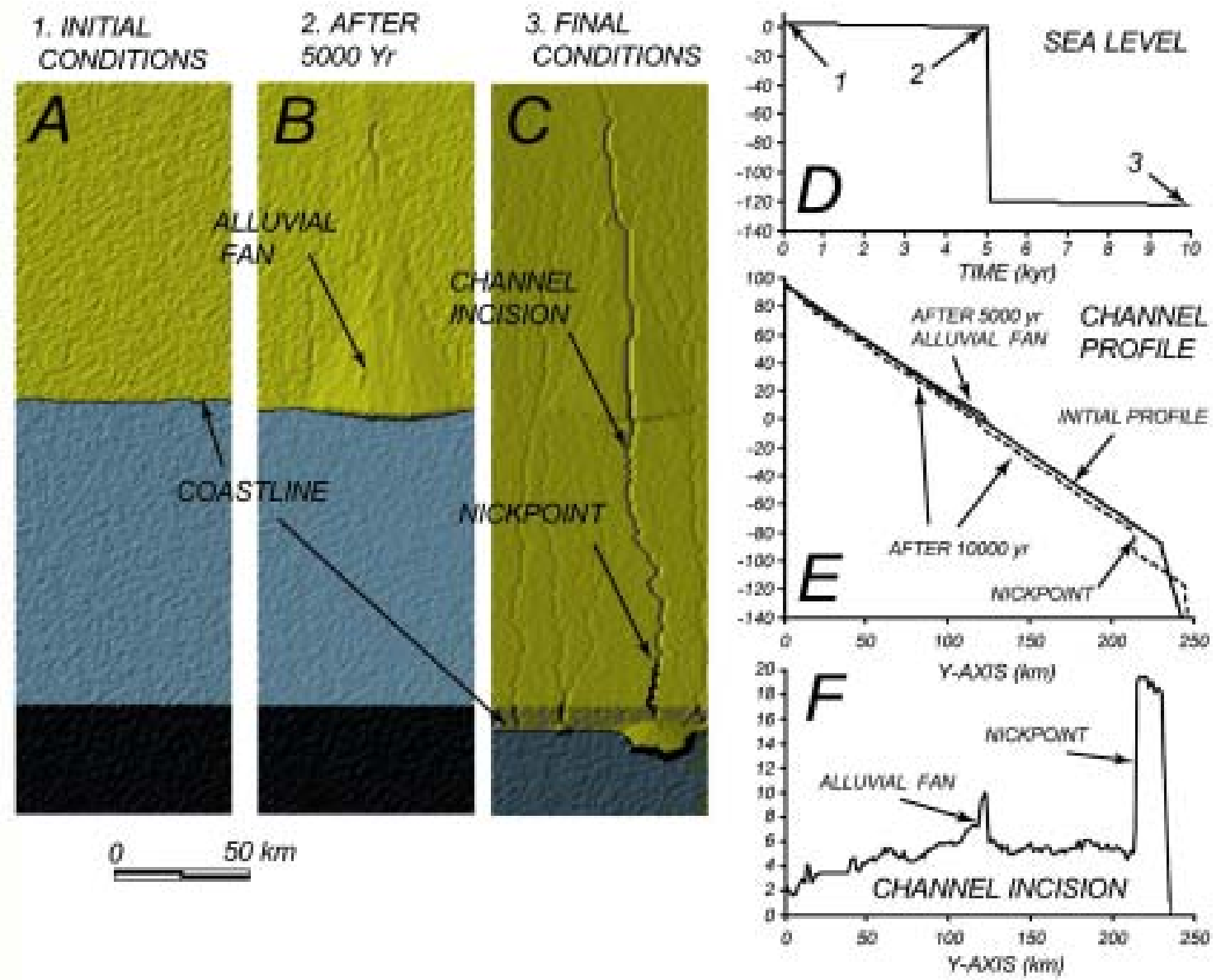

Figure 1: Influence of alluvial deposits on channel incision on continental shelves. Initial conditions (A) are a coastal plain (yellow) and shelf (blue) with low relief, random topography and a river at grade. After 5000 years of stable sea level, during which the river has produced an alluvial fan (B), sea level suddenly drops to below the shelf-slope break (D). Channels form on the newly exposed continental shelf, incising the fan deposit $(C, E)$. A nickpoint at the shelf edge cuts headward, resulting in deeper incision $(F)$. 
1. INITIAL CONDITIONS
2. AFTER

$7000 \mathrm{Yr}$

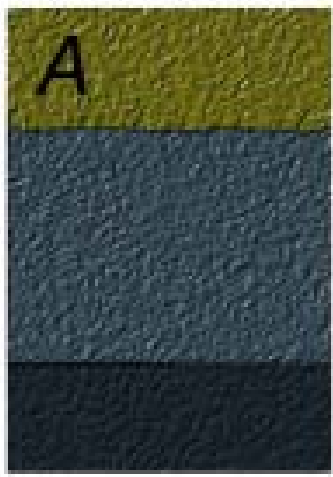

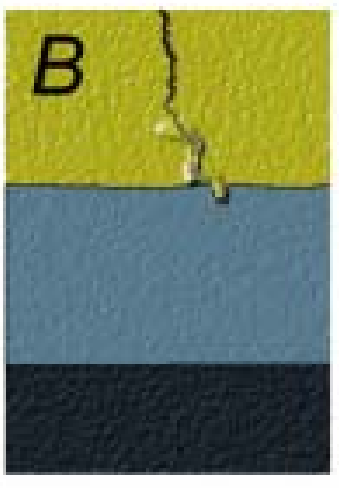
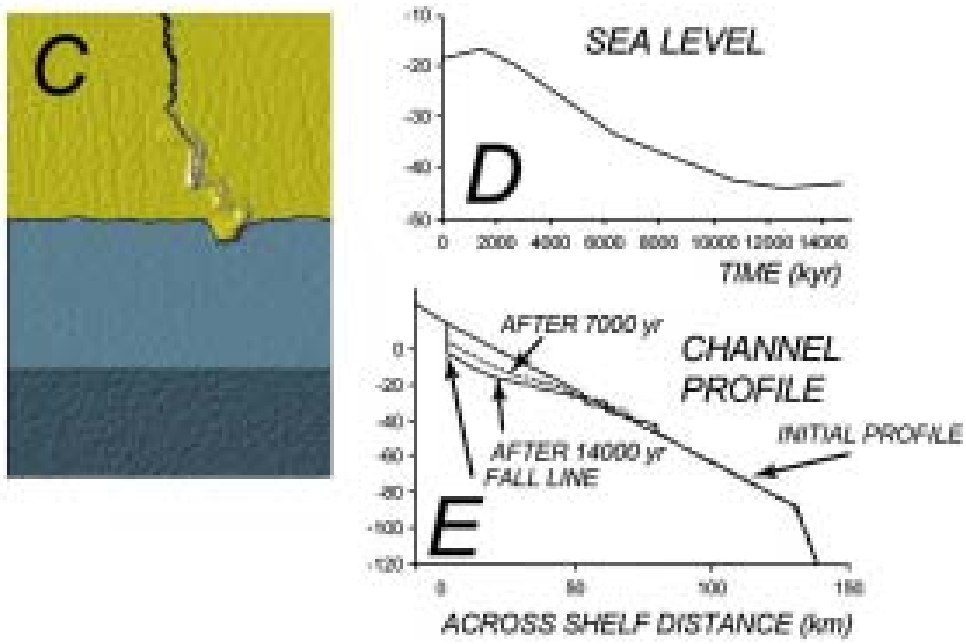

Figure 2: Influence of channel with an equilibrium slope smaller than the slope of the coastal plain and shelf on shelf incision As sea level gradually falls about $30 \mathrm{~m}$ (D), the channel cuts downward and seaward ( $B$ and $C$ ) leaving an escarpment at the contact between the coastal plain and more resistant rock (E).

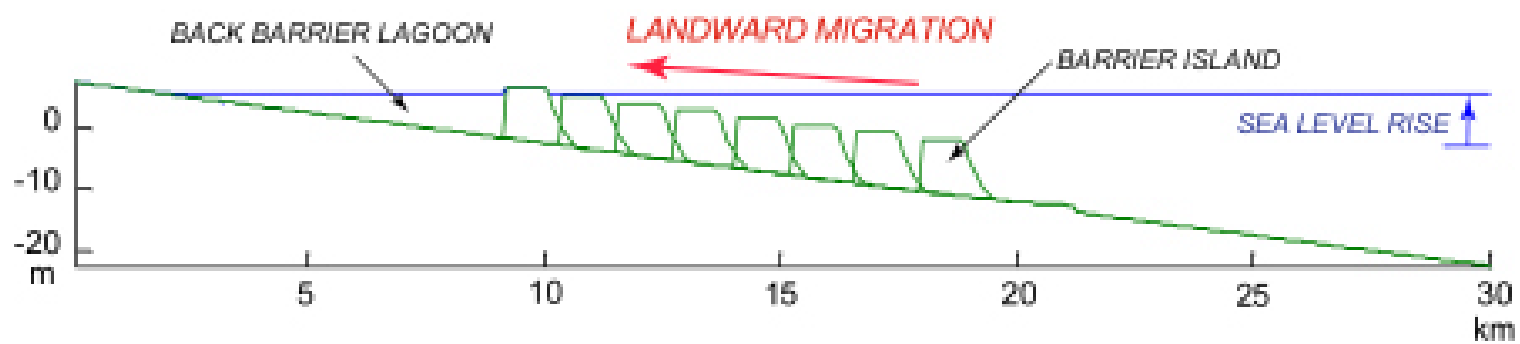

Figure 3: 2D model for barrier island formation and evolution. As sea level rises, the barrier island (green curve) translates landward as storm overwash translates sand from the shoreface to the back barrier lagoon. 


\section{BARRIER ISLAND EVOLUTION DURING SEA LEVEL RISE}
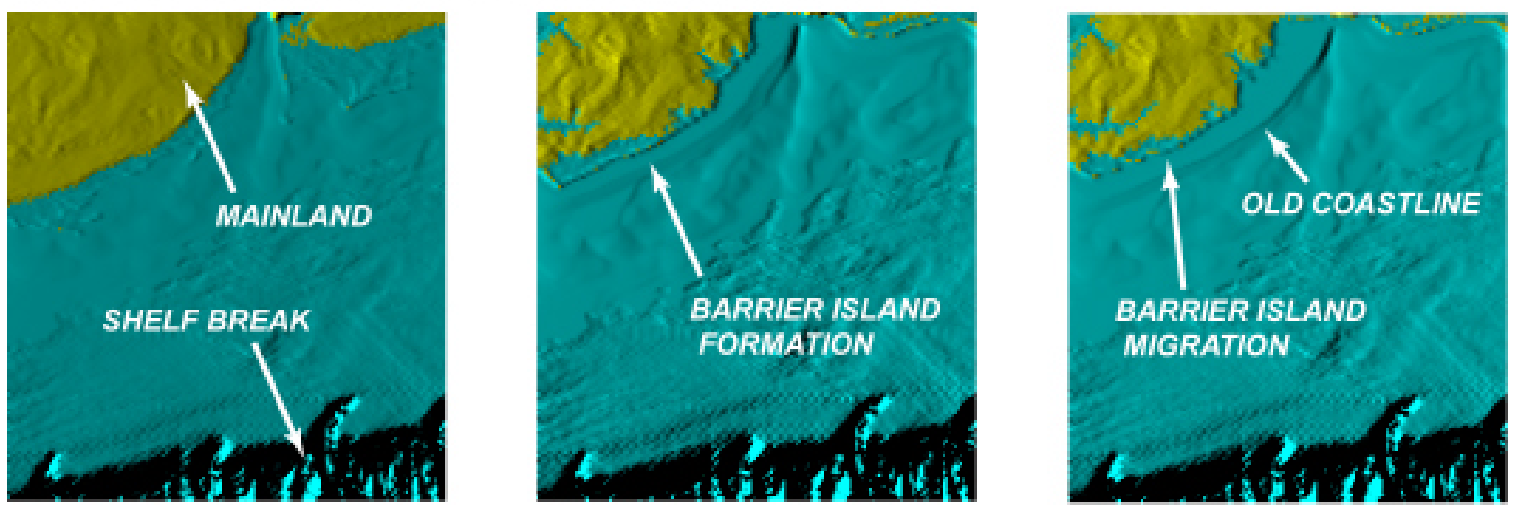

$0 \quad 50 \mathrm{~km}$

Figure 4 Preliminary results of a coupled 3D model for nearshore sediment transport and fluvial incision. In this example, the model is applied to a section of the continental shelf south of the Hudson River. As sea level rises (left to right panels), the coastline is modified by flooding of terrestrial features and nearshore transport of sediment across and along the shoreface, producing a set of migrating barrier islands.

\section{IMPACT/APPLICATIONS}

Model simulations provide information about channel incision rate, channel density, and channel burial for acoustic analyses of buried channel features on the continental shelf that contribute to geoclutter.

\section{PUBLICATIONS}

Fagherazzi S., Wiberg P.L., Howard A.D., Tidal flow field in a small basin. J. Geoph. Res. Oceans, (accepted pending revisions).

Fagherazzi S., Basic flow field in a tidal basin, Geophysical Res. Lett., 29,(8) 13787-13789, 2002.

Fagherazzi, S., A.D. Howard, and P.L. Wiberg, 2002. An implicit finite-difference method for drainage-basin evolution. Water Resources Research, 10.1029/2001WR000721

Howard, A.D., S. Fagherazzi, and P.L. Wiberg, Fluvial erosion of continental shelves during sea level low stands, American Geophysical Union, Transactions, Spring Meeting, 2002. 